\title{
Sensibilidade in vitro a antimicrobianos de Corynebacterium pseudotuberculosis isolados de pequenos ruminantes da região Centro- Norte do Estado da Bahia
}

\author{
In vitro antimicrobial susceptibility of Corynebacterium pseudotuberculosis isolated \\ from small ruminants from the North-Central region of the State of Bahia
}

Maiana Maria Mattos ${ }^{1}$, Laerte Marlon Santos ${ }^{2}$, Ricardo Wagner Portela ${ }^{3 *}$, Roberto Paulo Correia de Araújo $^{4}$

${ }^{1}$ Doutoranda do Programa de Pós-graduação de Processos Interativos de Órgãos e Sistemas, UFBA; ${ }^{2}$ Doutorando do Programa de Pós-graduação em Ciência Animal nos Trópicos; ${ }^{3}$ Professor Associado do Instituto de Ciências da Saúde; ${ }^{4}$ Professor Titular Livre Docente de Bioquímica. Instituto de Ciências da Saúde, UFBA.

\begin{abstract}
Resumo
Introdução: corynebacterium pseudotuberculosis é uma bactéria com importância em medicina veterinária por ser o agente etiológico da Linfadenite Caseosa (LC) em pequenos ruminantes. A doença leva a perdas econômicas devido a condenação de carcaças, diminuição de produtividade e redução do valor comercial do couro dos animais acometidos. O tratamento da doença é pouco eficaz, pois os agentes antimicrobianos não conseguem atravessar a barreira dos granulomas, mas tem sido proposta a inoculação intracapsular de antibióticos como tratamento e como medida de prevenção de contaminação ambiental. Objetivo: devido a esse fato, o presente estudo teve como objetivo avaliar a sensibilidade in vitro de isolados clínicos de Corynebacterium pseudotuberculosis isolados de animais da região Centro-Norte do estado da Bahia. Metodologia: foram retirados material de granulomas de 11 animais de uma fazenda na região acima mencionada, e as bactérias foram isoladas a partir desse material. Esses isolados então foram submetidos a metodologia de difusão em disco de ágar utilizando-se discos impregnados com doze antibióticos diferentes. Resultados: 90,9\% (10/11) dos isolados foram resistentes a oxacilina. Com relação à sensibilidade, $100 \%$ dos isolados foram sensíveis a ampicilina, amicacina, amoxicilina, cefalotina, ceftriaxona, ciprofloxacina, enrofloxacina, neomicina e penicilina, enquanto $90,9 \%$ destes apresentaram sensibilidade a bactericina e doxiciclina. Conclusão: pode-se concluir que os isolados de $C$. pseudotuberculosis da região estudada apresentam sensibilidade a diversos antibióticos, o que pode facilitar na escolha de um antimicrobiano com menor toxicidade para fins de tratamento com inoculação intracapsular do medicamento.
\end{abstract}

Palavra-Chave: Antibiograma. Linfadenite. Patologia Veterinária.

\begin{abstract}
Background: corynebacterium pseudotuberculosisis important bacteria in veterinary medicine because it is the Etiologic Agent of Caseous Lymphadenitis (CL) in small ruminants. The disease leads to economic losses due to condemnation of carcasses, productivity decrease and leather commercial value reduction of affected animals affected. The treatment of the disease is not very effective, because antimicrobial agents cannot cross the barrier of granulomas, but it has been proposed the intracapsular inoculation of antibiotics as treatment and as a measure of prevention of environmental contamination. Objective: due to this fact, the present study aimed to evaluate the in vitro susceptibility of clinical isolates of Corynebacterium pseudotuberculosis isolated from animals in the North Central region of the State of Bahia. Methodology: granuloma material were removed from 11 animals from a farm in the above mentioned area, and the bacteria were isolated from this material. These isolated bacteria were then subjected to disk diffusion method of agar using disks impregnated with twelve different antibiotics. Results: 90,9\% (10/11) the isolated bacteria were resistant to oxacillin. With respect to sensitivity, $100 \%$ of the isolates bacteria were susceptible to amikacin, ampicillin, amoxicillin, cephalotin, ceftriaxone, ciprofloxacin, enrofloxacin, neomycin and penicillin, while $90.9 \%$ of these showed sensitivity to bacitracin and doxycycline. Conclusion: it can be concluded that the isolated bacteria of C. pseudotuberculosis from the region studied present sensitivity to different antibiotics, which can facilitate the choice of a less toxic antimicrobial for treating with intracapsular inoculation of the medicine.
\end{abstract}

Keywords: Microbial Sensitivity Tests. Lymphadenitis. Veterinary Pathology.

\section{INTRODUÇÃO}

A Linfadenite Caseosa (LC) é uma doença infectocontagiosa crônica que afeta pequenos ruminantes

Correspondente/Corresponding: *Ricardo Wagner Portela - Instituto de Ciências da Saúde - UFBA - End: Av. Reitor Miguel Calmon S/N Canela salvador-Ba CEP: 40231-300 - E-mail: rwportela@gmail.com - Tel: (71)3235-9682 (ovinos e caprinos), caracterizada pela formação de granulomas em linfonodos e órgãos internos, tais como pulmões, baço e fígado (ALVES; SANTIAGO; PINHEIRO, 2007; DORELLA et al., 2009). É considerada uma zoonose ocupacional que acomete veterinários e trabalhadores da área agrícola em geral (BASTOS et al., 2012), o que baseia a necessidade de medidas de biossegurança por profissionais que trabalham diretamente com animais de 
produção (HEGGELUND et al., 2015)

A LC é causada por Corynebacterium pseudotuberculosis, um bacilo Gram-positivo, pleomórfico, não esporulado, anaeróbico facultativo, intracelular, pertencente à família Corynebacteriaceae (CORREA et al., 2018; DORELLA et al., 2006). Como uma bactéria intracelular facultativa, é capaz de sobreviver e crescer em macrófagos, o que pode ser um fator de escape do sistema imune do hospedeiro. (AYERS, 1977; MCKEAN; DAVIES; MOORE, 2005; PATON et al., 1994). Uma característica importante desse microrganismo é uma parede celular composta principalmente de peptideoglicanos, arabinogalactano e ácidos micólicos, e o alto conteúdo de guanina e citosina no genoma (GUIMARÃES et al., 2011). A transmissão ocorre por contato direto, principalmente, através do contato da secreção dos granulomas com feridas dos animais, mas também mediada por agulhas e ou materiais/equipamentos cirúrgicos contaminados ou via aerógena (ALVES; SANTIAGO; PINHEIRO, 2007; RADOSTITS; BLOOD; GAY, 2007; RIET-CORREA 2007; WILLIAMSON, 2001). A ruptura do granuloma libera um grande número de bactérias na pele e na lã, e resulta na contaminação subseqüente do ambiente de criação dos animais (FONTAINE; BAIRD, 2008)

A LC tem alta prevalência em países em desenvolvimento e tem sido apontada como uma das principais causas de perdas econômicas na criação de caprinos e ovinos na África e na América do Sul (GUIMARAES et al., 2011; RUIZ et al., 2011). No Brasil, o Norte e Nordeste possuem uma alta prevalência de LC nos rebanhos de pequenos ruminantes, sendo relatados casos da doença por $85 \%$ de produtores na região Norte e $41 \%$ no Nordeste (OLIVEIRA et al., 2011). Essa alta prevalência de LC está relacionada a uma elevada resistência das bactérias a temperaturas extremas e diferentes umidades, e a capacidade dessas bactérias de invadir o hospedeiro rapidamente através de lesões de pele (SOARES et al., 2013). Isso representa um significativo problema à ovinocaprinocultura brasileira, principalmente devido às perdas atribuídas à infecção por C. pseudotuberculosis, as quais incluem diminuição da produção de leite e de lã, diminuição do ganho de peso, valor reduzido de couros devido a cicatrizes, o custo do tratamento da lesão e, eventualmente, a morte do animal. (ALVES; PINHEIRO; ANDRIOLI, 2002; AYERS, 1977; GUIMARÃES et al., 2011; MCKEAN; DAVIES; MOORE, 2005; PATON et al., 1994). Com isso, a LC continua sendo um desafio importante para a pecuária de ovinos e caprinos, limitando sua lucratividade. $O$ intenso mercado e movimentação de pequenos ruminantes, sem as necessárias medidas de biossegurança, são importantes obstáculos para o controle da linfadenite caseosa, mantendo sua prevalência em níveis elevados, o que indica que medidas específicas de controle devem ser adotadas. (GUIMARAES et al., 2011).

A erradicação da LC é difícil porque o seu diagnóstico baseia-se geralmente em sinais clínicos (visualização de granulomas nos gânglios linfáticos), que geralmente aparecem tardiamente no processo da infecção. A ineficácia da terapia medicamentosa é causada principalmente pela dificuldade da grande maioria dos antibióticos atravessarem a membrana dos granulomas, dessa forma não atingindo a região onde está grande parta das bactérias (DORELLA et al., 2006; SANTOS et al., 2016). Com isso, o tratamento disponível é a retirada do conteúdo caseoso das lesões, o que pode acarretar contaminação ambiental caso não ocorra a devida manipulação do material retirado das lesões. Como uma possível alternativa de tratamento para a doença, tem-se pesquisado a inoculação intracapsular de agentes antimicrobianos nos granulomas (ALVES; SANTIAGO; PINHEIRO, 2007; SENTURK; TEMIZEL, 2006), o que evitaria a abertura das lesões e possíveis contaminações do ambiente com a bactéria.

Portanto, o objetivo deste estudo foi avaliar a sensibilidade e/ou resistência antimicrobiana in vitro de isolados de Corynebacterium pseudotuberculosis obtidos de lesões granulomatosas de caprinos e ovinos procedentes de uma fazenda do município de Capim Grosso, localizado no Centro-Norte do estado da Bahia, frente a diferentes antibióticos disponíveis comercialmente.

\section{METODOLOGIA}

\section{Cepas e isolados clínicos de $C$. pseudotuberculosis}

No presente estudo, foram utilizadas 12 cepas de C. pseudotuberculosis, sendo uma cepa padrão utilizada como controle (1002) e 11 isolados clínicos obtidos a partir de material caseoso coletado de caprinos e ovinos acometidos com suspeita clínica de LC. Esses animais estavam localizados em uma fazenda no município de Capim Grosso, localizado na região Centro-Norte do estado da Bahia, e essa fazenda obtinha animais de toda a região para procedimento de engorda e posterior envio dos animais para abatedouro. Esses animais tiveram a retirada completa do conteúdo da lesão granulomatosa através de procedimento cirúrgico. 0 material foi diretamente coletado em frascos estéreis, os quais foram encaminhados sob refrigeração para o Laboratório de Imunologia e Biologia Molecular (LABIMUNO) do Instituto de Ciências da Saúde da Universidade Federal da Bahia (ICS/UFBA), onde foram realizados os procedimentos de isolamento e identificação dos agentes microbianos.

Esse estudo tem a aprovação do Comitê de Ética em Uso de Animais em Experimentação da Escola de Medicina Veterinária e Zootecnia da Universidade Federal da Bahia sob o número de protocolo 35/2017.

\section{Isolamento e identificação bacterianos}

Para isolamento da bactéria a partir do material dos granulomas, as amostras coletadas dos animais foram inoculadas em ágar sangue suplementado com 
$5 \%$ de sangue de ovino. Após esse procedimento, as placas foram incubadas em estufa $\left(2 \%\right.$ de $\left.\mathrm{CO}_{2}\right)$ durante $48 \mathrm{~h}$ a $37^{\circ} \mathrm{C}$. As colônias isoladas foram caracterizadas macroscopicamente, coradas pelo método de Gram e submetidas a provas bioquímicas para sua devida identificação. Essas provas bioquímicas incluíram a verificação de produção de catalase, e de fermentação de glicose, maltose, sacarose e ureia, lactose, trealose. Também foram conduzidos os testes de salicina e de observação de motilidade (SÁ et al., 2013).

\section{Ensaios de determinação da sensibilidade de isolados de C. pseudotuberculosis frente a antibióticos comerciais.}

A avaliação da resistência ou susceptibilidade das cepas 1002 (cepa padrão) e dos isolados clínicos a antibióticos disponíveis comercialmente foi realizada pela metodologia de difusão em disco, seguindo uma metodologia proposta por BAUER et al., 1966 e também o recomendado pelo Clinical and Laboratory Standards Institute (CLSI, 2018). As cepas foram crescidas em caldo Brain-Heart Infusion (BHI) a $37^{\circ} \mathrm{C}$ por 24 horas. Após 24 horas, ajustou-se a turbidez da cultura, de modo a obter uma turbidez óptica comparável à leitura de densidade óptica de 0,5 da solução padrão de McFarland (CLSI, 2003).

Em placas de Petri contendo ágar $\mathrm{BHI}$, foram adicionados $1 \mathrm{~mL}$ do inóculo em caldo $\mathrm{BHI}$ contendo o microrganismo. Com o auxílio de um swab estéril, o inoculo foi disseminado de forma suave em todas as direções na placa de Petri, procurando abranger toda a superfície. Esse procedimento foi realizado em fluxo laminar e em duplicata. Aguardou-se 5 minutos para que o inóculo fosse completamente absorvido pelo ágar para serem posteriormente aplicados, com o auxílio de uma pinça estéril, os discos impregnados com os antibióticos, sendo distribuídos seis discos de antibióticos por cada placa de Petri. Os discos utilizados continham 11 diferentes antibióticos, os quais foram escolhidos por sua disponibilidade e por serem utilizados rotineiramente em clínica veterinária de animais de grande produção para uso em infecções por bactérias Gram-positivas. A marca de cada disco utilizado e a concentração de cada antibiótico estão representadas na Tabela 1. As placas foram invertidas 15 minutos após a colocação dos discos e incubadas por 48 horas em estufa a $37^{\circ} \mathrm{C}$. Os halos de inibição formados foram então medidos com o auxílio de uma régua graduada e comparados a padrões pré-estabelecidos para determinação de susceptibilidade de $S$. aureus a antibióticos, já que não existe um padrão estabelecidos para C. pseudotuberculosis (CLSI, 2018). Todos os ensaios foram realizados em duplicatas e foram consideradas as médias dos diâmetros dos halos nos dois experimentos independentes para comparação com o padrão de S. aureus (CLSI, 2018) e determinação se cada isolado era resistente ou sensível ao antibiótico.
Tabela 1 - Concentrações dos antibióticos nos discos utilizados e suas respectivas marcas comerciais.

\begin{tabular}{lll}
\hline Antibiótico & Marca Comercial & Concentração por disco $(\mu \mathrm{g})$ \\
\hline Amicacina & Cefar & $30 \mu \mathrm{g}$ \\
\hline Amoxicilina & Cefar & $10 \mu \mathrm{g}$ \\
\hline Ampicilina & Bio-Rad & $10 \mu \mathrm{g}$ \\
\hline Bacitracina & Cefar & $130 \mu \mathrm{g}$ \\
Cefalotina & Cefar & $30 \mu \mathrm{g}$ \\
Ceftriaxona & Laborclin & $30 \mu \mathrm{g}$ \\
\hline Ciprofloxacina & Cefar & $5 \mu \mathrm{g}$ \\
\hline Doxiciclina & DME & $30 \mu \mathrm{g}$ \\
Enrofloxacina & DME & $5 \mu \mathrm{g}$ \\
\hline Neomicina & Cefar & $30 \mu \mathrm{g}$ \\
\hline Oxacilina & Cefar & $1 \mu \mathrm{g}$ \\
\hline Penicilina & Cefar & $130 \mu \mathrm{g}$ \\
\hline
\end{tabular}

Fonte: Autoria própria

\section{RESULTADOS}

C. pseudotuberculosis foi devidamente isolado e identificado a partir do conteúdo das lesões granulomatosas dos onze animais utilizados nesse experimento. Todos os isolados apresentaram resultado positivo na prova de Gram e tinham aparência típica de colônia de C. pseudotuberculosis (friável e com coloração esbranquiçada a amarelada). Os resultados das provas bioquímicas mostraram que todos os isolados clínicos apresentaram atividade de catalase, foram urease positivos e salicina negativos. $72,72 \%$ (8/11) foram capazes de fermentar a glicose e $54,54 \%$ (6/11) fermentaram maltose e $100 \%$ não fermentaram a sacarose. Nenhum isolado apresentou motilidade e e não fermentaram lactose, sacarose e nem trealose (Tabela 2).

Os resultados do teste de sensibilidade pelo método de disco difusão (Tabela 3) indicaram uma elevada sensibilidade dos isolados clínicos de $C$. pseudotuberculosis aos agentes antimicrobianos, e 90,9\% (10/11) demonstraram resistência para a oxacilina, com exceção do isolado clínico 531, que mostrou-se sensível. 11 isolados clínicos (100\%) apresentaram sensibilidade a amicacina, ampicilina, amoxicilina, cefalotina, ceftriaxona, ciprofloxacina, enrofloxacina, neomicina e penicilina, enquanto 10 (90,90\%) isolados foram sensíveis a bacitracina e doxiciclina.

Com relação a diferentes casos de resistência em uma mesma cepa ou isolado clínico, pode-se verificar que a cepa padrão 1002 mostrou-se resistente a oxacilina, amicacina e neomicina. 0 isolado clínico 522 mostrou-se resistente a bacitracina, doxiciclina e oxacilina. Nove isolados $(81,81 \%)$ apresentaram resistência somente a oxacilina, e somente o isolado 531 foi susceptivel a todos os antibióticos testados. 
Tabela 2 - Provas bioquímicas dos isolados clínicos utilizados nesse estudo. As provas bioquímicas foram repetidas duas vezes para sua devida confirmação. Em resultados contraditórios, era realizada mais uma repetição. As sinalizações utilizadas significam (+) positivo e (-) negativo.

\begin{tabular}{|c|c|c|c|c|c|c|c|c|c|c|c|c|}
\hline \multirow{2}{*}{ Provas Bioquímicas } & & \multicolumn{11}{|c|}{ Identificação do isolado C. pseudotuberculosis } \\
\hline & & 509 & 510 & 522 & 524 & 531 & 562 & 563 & 564 & 568 & 570 & 583 \\
\hline Gram & + & + & + & + & + & + & + & + & + & + & + & + \\
\hline Catalase & + & + & + & + & + & + & + & + & + & + & + & + \\
\hline Glicose & + & + & + & + & - & - & + & + & + & + & - & + \\
\hline Lactose & - & - & - & - & - & - & - & - & - & - & - & - \\
\hline Maltose & + & + & + & + & + & - & + & + & + & - & - & - \\
\hline Sacarose & - & - & - & - & - & - & - & - & - & - & - & - \\
\hline Trealose & - & - & - & - & - & - & - & - & - & - & - & - \\
\hline Salicina & - & - & - & - & - & - & - & - & - & - & - & - \\
\hline Ureia & + & + & + & + & + & + & + & + & + & + & + & + \\
\hline Motilidade & - & - & - & - & - & - & - & - & - & - & - & - \\
\hline
\end{tabular}

Fonte: Autoria própria

Tabela 3 - Perfil de sensibilidade antimicrobiana de isolados clínicos e da cepa referência 1002 de Corynebacterium pseudotuberculosis pelo método de difusão em disco. A classificação da cepa como resistente, intermediária ou sensivel foi feita de acordo com o proposto pelo CLSI, 2018. Os resultados aqui são expressão de dois experimentos independentes. (S) expressa sensibilidade da cepa/isolado ao antibiótico, e (R) se os mesmos foram resistentes.

\begin{tabular}{|c|c|c|c|c|c|c|c|c|c|c|c|c|}
\hline \multirow{2}{*}{ Antibiótico } & \multicolumn{12}{|c|}{ Identificação do isolado/cepa de C. pseudotuberculosis } \\
\hline & 1002 & 509 & 510 & 522 & 524 & 531 & 562 & 563 & 564 & 568 & 570 & 583 \\
\hline Ampicilina & S & S & S & S & S & S & S & S & S & S & S & S \\
\hline Amoxicilina & $S$ & $S$ & S & $\mathrm{S}$ & S & $\mathrm{S}$ & S & $\mathrm{S}$ & S & S & $S$ & S \\
\hline Amicacina & $\mathrm{R}$ & S & S & S & $S$ & S & S & S & S & S & S & $S$ \\
\hline Bacitracina & S & S & S & $R$ & S & S & S & S & S & S & S & $S$ \\
\hline Cefalotina & $S$ & S & S & S & S & S & S & S & S & S & S & $S$ \\
\hline Ceftriaxona & S & $S$ & $S$ & $S$ & $S$ & S & S & S & S & S & S & $S$ \\
\hline Ciprofloxacina & S & S & S & S & S & S & S & S & S & S & S & $S$ \\
\hline Doxiciclina & $S$ & S & S & $\mathrm{R}$ & S & S & S & S & S & S & S & $S$ \\
\hline Enrofloxacina & S & $S$ & $S$ & S & $S$ & S & S & S & S & S & S & $S$ \\
\hline Neomicina & $\mathrm{R}$ & $S$ & S & S & S & S & S & S & S & S & S & $S$ \\
\hline Oxacilina & $R$ & $\mathrm{R}$ & $R$ & $R$ & $R$ & S & $\mathrm{R}$ & $R$ & $R$ & $R$ & $R$ & $\mathrm{R}$ \\
\hline Penicilina & S & $S$ & S & S & $S$ & $S$ & $S$ & $S$ & $S$ & $S$ & $\mathrm{~S}$ & $S$ \\
\hline
\end{tabular}

Fonte: Autoria própria

\section{DISCUSSÃO}

A LC é uma doença que afeta de forma significativa a ovinocaprinocultura brasileira, principalmente pequenos produtores da região semiárida do Nordeste. 0 tratamento sistêmico com antibióticos é ineficaz, e o procedimento mais difundido atualmente é a extirpação cirúrgica das lesões granulomatosas, o que pode levar a uma contaminação ambiental. Uma das opções de tratamento sendo considerada hoje em dia é a inoculação intracapsular de substâncias microbicidas, e por isso o presente trabalho visou verificar quais os antibióticos apresentavam maior grau de sensibilidade perante isolados de C. pseudotuberculosis provindos de uma importante região criadora de ovinos e caprinos da Bahia, e encontramos sensibilidade significativa a diversos antibióticos.

As principais características de C. pseudotuberculosis que são importantes para a sua identificação a serem levadas em consideração são: a aparência friável da colônia e sua coloração esbranquiçada a amarelada, resultado positivo no teste de Gram, fermentação de glicose, galactose, glicose e maltose, não fermentação de lactose, xilose e trealose, presença de $\beta$-hemólise no teste de Christie-Atkins-Munch-Petersen (CAMP), ausência de motilidade e resultado variável no teste de redução de nitrato de acordo com o biovar envolvido. (JONES; COLLINS, 1986; QUINN et al., 2005). Mas de acordo com resultados prévios descritos na literatura (KONEMAM et al., 2008), pode haver uma variação de perfil fermentativo de glicose e lactose, bem como de liquefação de gelatina. Os resultados aqui apresentados sobre o perfil bioquímico dos isolados clínicos obtidos na região Centro-Norte da Bahia confirmam uma boa parte desses achados, mas vimos também que houve uma variação no perfil de fermentação da maltose, mesmo com os ensaios repetidos por duas vezes e com a confirmação da ausência de contaminantes. Esse perfil pouco usual pode ser justificado pela extensa variação do perfil fermentativo dos isolados clínicos relatados por Çetinkaya et al. (2002). 
C. pseudotuberculosis é exigente do ponto de vista nutricional, crescendo bem em meios enriquecidos como ágar sangue, ágar $\mathrm{BHI}$ (Brain Heart Infusion) ou caldo $\mathrm{BHI}$ enriquecidos com soro animal (COSTA, 2002; QUINN et al., 2005). Para avaliar a sensibilidade antimicrobiana, o ágar Mueller-Hinton é considerado o melhor teste de sensibilidade contra bactérias não fastidiosas por apresentar reprodutibilidade aceitável (CLSI, 2005). Bactérias como C. pseudotuberculosis exigem meios enriquecidos como ágar sangue ou ágar $\mathrm{BHI}$ para um crescimento satisfatório (MOURA-COSTA et al., 2008). Para tanto, foi utilizado o meio BHI para a realização do teste da susceptibilidade aos antimicrobianos pelos métodos de difusão em disco. $O$ ágar sangue não foi utilizado devido o aumento da atividade hemolítica com o acréscimo de Tween 80 (SUTHERLAND; SPEIJERS; ANDRES, 1989), dificultando a leitura dos halos de inibição.

Os resultados do teste de difusão em disco com 12 antibióticos confirmam a elevada sensibilidade in vitro de C. pseudotuberculosis aos antimicrobianos, a qual já foi relatada em outros países, como na Índia (MOHAN; VATHSALA; JAYAPRAKASAN, 2008), na Etiópia (ABEBE; SISAY TESSEMA, 2015), Egito (ALGAMMAL, 2016), Venezuela (DUNO et al., 2016) e Itália (DOMENIS et al., 2018), e mesmo em isolados de C. pseudotuberculosis produtores de biofilmes (SÁ et al., 2013). Esse mesmo resultado também foi descrito em isolados clínicos de $C$. pseudotuberculosis obtidos de lesões de linfangite ulcerativa de equinos (MAMMAN; MSHELIA; FADIMU, 2011; NORMAN et al., 2014; RHODES et al., 2015). Esse quadro de susceptibilidade disseminada pode ser devido ao fato de que há pouca pressão seletiva por uso de antibióticos na clínica de pequenos ruminantes, já que os veterinários que atuam nas unidades produtoras já optam pela extirpação cirúrgica das lesões de LC e não procedem a uma antibioticoterapia dos animais. $\mathrm{O}$ uso intensivo e indiscriminado de antibióticos é fator importante para o desenvolvimento de resistência em bactérias (TELLO; AUSTIN; TELFER, 2012) e esse cenário pode ser evitado na clinica de caprinos e ovinos através de um uso racional de tais medicamentos.

Um estudo desenvolvido por Reshma et al. (2017) envolveu o isolamento e detecção molecular de C. pseudotuberculosis de granulomas de um caprino, os quais estavam localizados perto do umbigo. No antibiograma observou-se sensibilidade à tetraciclina e ceftriaxona e resistente a amoxicilina-ácido clavulânico, enrofloxacina e cotrimoxazol. Em outro estudo, 66 isolados de C. pseudotuberculosis obtidos de ovinos e caprinos do Sudão foram testados quanto a sensibilidade a 16 agentes antimicrobianos. Os isolados se apresentaram altamente sensíveis à nitrofurantoína, cloranfenicol, rifampacina, cotrimoxazole, eritromicina e ampicilina, foram moderadamente sensíveis à meticilina, canamicina, gentamicina e tetraciclina, mas foram resistentes ao ácido nalidíxico, colistina, novobiocina, penicilina, cloxacilina e estreptomicina (ABDEL WAHAB; SHIGIDI, 2013). A diferença no perfil de sensibilidade/resistência obtidas nesses estudos com o presente experimento demonstra a variação desse perfil de acordo com diferentes regiões geográficas, e reforça a necessidade de estudos de antibiograma antes da aplicação indiscriminada de algum agente antibiótico.

A C. pseudotuberculosis é sensível in vitro a vários antimicrobianos usados na clínica veterinária, que incluem fármacos dos grupos dos beta-lactâmicos e derivados, aminoglicosídeos, fluorquinolonas, macrolídeos, tetraciclinas e rifampicina (COSTA, 2002). Mamman, Mshelia e Fadimu (2011) observaram que as fluoroquinolonas (especialmente a ciprofloxacina) e as penicilinas (especialmente a amoxicilina) exibem consistente eficácia contra bactérias Gram-positivas e especialmente $C$. pseudotuberculosis. Isso está de acordo com o nosso estudo, que teve $100 \%$ das cepas testadas sensiveis a ciprofloxacina e a amoxicilina. Entretanto, Duno et al. (2016) e Abdel Wahab e Shigidi (2013) já ocorrem casos de isolados resistentes a penicilina, e o fato de que os veterinários recorrem a mesma como primeira escolha caso façam o tratamento da LC deve ser reavaliado, e mais uma vez indica que o tratamento deve ser precedido de um ensaio de antibiograma.

Mesmo que a C. pseudotuberculosis seja sensível a uma significativa variedade de antibióticos, estes não são eficazes pois não penetram na cápsula fibrosa dos granulomas, fazendo da antibioticoterapia uma estratégia ineficaz e de alto custo. 0 tratamento terapêutico se torna mais ineficaz se for levado em consideração também que o patógeno é intracelular (ROBAJ et al., 2017), sendo esta uma propriedade de virulência que limita a ação de vários antimicrobianos convencionais (RADOSTITS; BLOOD; GAY, 2007). Portanto, algumas alternativas estão sendo avaliadas. Senturk e Temizel (2006) obteve bons resultados com a administração intracapsular de rifamicina combinada à tetraciclina em ovinos, mas ressalta a possibilidade de baixa eficiência caso haja resistência a rifamicina por parte das microbactérias. Esta proposta terapêutica, entretanto, não avaliou a redução dos granulomas internos, sendo necessária a observação mais detalhada no experimento (BAIRD, 2006). Também foi possível reduzir a disseminação bacteriana com administração intracapsular de penicilina ou tetraciclina ou mesmo após ruptura espontânea, mas ainda não existem estudos conclusivos a respeito destes resultados. (SMITH; SHERMAN, 2009). O uso da tulatromicina subcutânea se mostrou parcialmente viável em experimento com caprinos (WASHBURN et al., 2013). O presente estudo demonstra que há uma grande variedade de antibióticos a serem utilizados, o que aumenta as opções do veterinário que atua em campo, pois o mesmo pode optar por medicamentos com menor custo caso seja necessário. Também deve-se levar em consideração que antibióticos com menor toxicidade podem ser escoIhidos para administração intracapsular, para que dessa forma haja um combate in loco da bactéria com reduzida agressão aos tecidos e menor possibilidade de necrose. 


\section{CONCLUSÃO}

O presente estudo demonstrou elevada sensibilidade de isolados clínicos de C. pseudotuberculosis a agentes antimicrobianos comerciais pelo teste de difusão em disco, exceto para o antimicrobiano oxacilina, para o qual os isolados se apresentaram resistentes. A cepa padrão 1002 se mostrou resistente a amicacina, neomicina e oxaciclina. Estes resultados podem orientar médicos veterinários que atuam na região centro-norte do estado da Bahia ou mesmo no estado a assumir técnicas alternativas de tratamento da linfadenite caseosa.

\section{REFERÊNCIAS}

ABEBE, D.; SISAY TESSEMA, T. Determination of Corynebacterium pseudotuberculosis prevalence and antimicrobial susceptibility pattern of isolates from lymph nodes of sheep and goats at an organic export abattoir, Modjo, Ethiopia. Lett. appl. microbiol., Oxford, v.61, 2015.

ABDEL WAHAB, M. B.; SHIGIDI, M. T. A. Susceptibility of Corynebacterium pseudotuberculosis isolated from sheep and goats with caseous lymphadenitis to some antimicrobial agents. Sudan J. Vet. Res., Sudão, 2013.

ALGAMMAL, A. Molecular characterization and antibiotic susceptibility of corynebacterium pseudotuberculosis isolated from sheep and goats suffering from caseous lymphadenitis. Zag. Vet. J., [S.I], v. 44, n. 1, p. 1-8, June, 2016.

ALVES, F.; PINHEIRO, R.; ANDRIOLI, A. Linfadenite caseosa em caprinos e ovinos:recomendações e medidas profiláticas. Agropec. Catarin., Florianópolis, v. 3, p. 12-14, 2002.

ALVES, F. S. F.; SANTIAGO, L. B.; PINHEIRO, R. R. Linfadenite Caseosa: o estado da arte. EMBRAPA Documentos, [S.I], v. 74, p. 57, 2007.

AYERS, J. L. Caseous lymphadenitis in goats and sheep: a review of diagnosis, pathogenesis, and immunity corynebacterium pseudotuberculosis. J. Am. Vet. Med. Assoc., Chicago, v.171, p. 1251-1254, 1977.

BAIRD, G. Treatment of ovine caseous lymphadenitis. Vet. rec., London, v.159, n. 15, p. 500, 2006.

BASTOS, B.L. et al. Corynebacterium pseudotuberculosis: immunological responses in animal models and zoonotic potential. J. clin. cell immunol., Canada, p. S4-S5, 2012.

BAUER, A. W. et al. n.4, . Am. j. clin. pathol., Baltimore, v.45, p. 493496, 1966.

ÇETINKAYA, B. et al. Identification of Corynebacterium pseudotuberculosis isolates from sheep and goats by PCR. Vet. microbiol., Amsterdam, v. 88, p. 75-83, 2002.

CLSI. Performance standards for antimicrobial susceptibility testing. CLSI Supplement M100. 28th ed Wayne, PA: Clinical and Laboratory Standards Institute, 2018.

CLSI. Performance standards for antimicrobial susceptibility testing. Clinical and Laboratory Standards Institute. Fifteenth Informational Supplement. Wayne, Pennsylvania 19087-1898 USA, 2005.

CLSI. Performance standards for antimicrobial susceptibility testing . Methods for dilution antimicrobial susceptibility tests for bacteria that grow aerobically. 6 th ed. Wayne: Pennsylvania 19087-1898 USA, 2003.

CORREA, J. I. et al. In vivo and in vitro expression of five genes involved in Corynebacterium pseudotuberculosis virulence. AMB Express, Germany, v. 8, p. 89, 2018.
COSTA, L. F. de M. Corynebacterium pseudotuberculosis, o agente etiológico da linfadenite caseosa em caprinos. R. Ci. Méd. Biol., Salvador, v. 1, n. 1, p. 105-115, nov. 2002.

DOMENIS, L. et al. Caseous Lymphadenitis Caused by Corynebacterium pseudotuberculosis in Alpine Chamois (Rupicapra r. rupicapra): a review of 98 Cases. J. comp. pathol, Liverpool, v. 161, p.11-19, 2018.

DORELLA, F. A. et al. Corynebacterium pseudotuberculosis: microbiology, biochemical properties, pathogenesis and molecular studies of virulence. Vet. res, Paris, v.37, p. 201-218, 2006.

Antigens of Corynebacterium pseudotuberculosis ad prospects for vaccine development. Expert Rev. Vaccines, London, v. 8, n.2, p. 205-213, 2009.

DUNO, A. D. et al. Caracterización epidemiológica de la linfadenitis caseosa en rebaños caprinos de la península de Paraguaná, Venezuela. Rev. med. vet., Bogotá (Colombia), enero-junio, 2016.

FONTAINE, M.C.; BAIRD, G. J. Caseous lymphadenitis. Small Rumin. Res., Amsterdam, v. 76, p. 42-48, 2008.

GUIMARÃES, A. S. et al. Caseous lymphadenitis: epidemiology, diagnosis, and control. IIOAB J. India, v.2, p. 33-43, 2011.

HEGGELUND, L. et al. Corynebacterium pseudotuberculosis pneumonia in a veterinary student infected during laboratory work. Open Forum Infect. Dis., United States, v.2, n.2, p.ofv053, Apr. 2015.

JONES, D.; COLLINS, M. D. Irregular, nonsporing Gram-positive rods. In: SNEATH, P. H. A. et al. Bergey's manual of systematic bacteriology. 2. th. Baltimore: Williams and Wilkins, 1986. p. 1261-1282.

KONEMAN, E.W. et al. Diagnóstico microbiológico: texto e atlas colorido. In: Bacilos Gram-positivos aeróbicos e facultativos. Rio de Janeiro: Guanabara Koogan, 2008. p. 760-851.

MAMMAN, P.H.; MSHELIA, W.P.; FADIMU, I. E. Antimicrobial susceptibility of aerobic bacteria and fungi isolated from cases of equine ulcerative lymphangitis in Kano Metropolis, Nigeria. Asian J. Animal Sciences, Dubai, v. 5, n.3, 175-182, 2011.

MCKEAN, S.; DAVIES, F.; MOORE, R. Identification of macrophage induced genes of Corynebacterium pseudotuberculosis by differential fluorescence induction. Microbes infect., Paris, v. 7, 1352-1363, 2005.

MOHAN, P.; VATHSALA, M.; JAYAPRAKASAN, V. Comparative characterization of Corynebacterium pseudotuberculosis from goats in Kerala, India and reference strain. Small Rumin. Res., Amsterdam, v. 74, n. 1-3, p. 226-230, 2008.

MOURA-COSTA, L. F. et al. Evaluation of the humoral and cellular immune response to different antigens of Corynebacterium pseudotuberculosis in Canindé goats and their potential protection against caseous lymphadenitis. Vet. immunol. immunopathol., Amsterdam, v. 126, n. 1-2, p. 131-141, 2008.

NORMAN, T. E. et al. In vitro susceptibility of equine-obtained isolates of Corynebacterium pseudotuberculosis to gallium maltolate and 20 other antimicrobial agents. J. clin. microbiol.,Washington, v. 52, n. 7, p. 2684-2685, 2014.

OLIVEIRA, D. M. et al. Sequenciamento do genoma do Corynebacterium pseudotuberculosis e as implicações no diagnóstico e controle da linfadenite caseosa. Revista Brasileira de Higiene e Sanidade Animal, Fortaleza, v. 5, n.1, p. 19-28, jan./ jun. 2011.

PATON, M. W. et al. New infection with Corynebacterium pseudotuberculosis reduces wool production. Aust. vet. j., Victoria, v.71, n.2, 47-49, 1994. 
QUINN, P. et al. Microbiologia veterinária e doenças infecciosas. Porto Alegre: Artmed, 2005. cap. 10. p. 67-70.

RADOSTITS, O.M.; BLOOD, D.C.; GAY, C.C. Veterinary medicine: a textbook of the diseases of catlee, sheep, pigs, goats and horses. 9th ed. Philadelphia: Bailliere Tindall, 2007. p. 830-839.

RESHMA, P. S.et al. Isolation and molecular detection of Corynebacterium pseudotuberculosis from a case of umbilical abscess in a kid. Int. j. environ sci. technol., Tehran, v. 6, n. 5, p. 2827-2832, 2017.

RIET-CORREA, F. Linfadenite caseosa. In: RIET-CORREA, F. et al. (Eds.) Doenças de ruminantes e eqüídeos. 3a ed. Santa Maria: Pallotti, 2007. p. 347-352.

RHODES, D. M. et al. Minimum inhibitory concentrations of equine corynebacterium pseudotuberculosis isolates (1996 - 2012). J. vet. intern. med., Philadelphia, v. 29, p. 327-332, 2015.

ROBAJ, A. et al. Frequency and antimicrobial susceptibility of bacterial isolates from Caseous Lymphadenitis in sheep in Kosovo. Bulg. J. Agric. Sci., Bulgaria, v. 23, n. 6, 1033-1036, 2017.

RUIZ, J. C. et al. Evidence for reductive genome evolution and lateral acquisition of virulence functions in two Corynebacterium pseudotuberculosis strains. PLos ONE, San Francisco, v. 6, n.4, Apr. 2011.

SÁ, M. da C. A. et al. Activity of disinfectants and biofilm production of Corynebacterium pseudotuberculosis. Pesq. vet. bras., Rio de janeiro, v. 33, n. 11, p. 1319-1324, 2013.

SANTOS, E. M. S. et al. Antígenos de Corynebacterium pseudotuberculosis com potencial promissor para o desenvolvimento de vacinas contra linfadenite caseosa: uma revisão de literatura. Cad. Ciênc. Agrá., Minas Gerais, v. 8, n. 2, p. 90-99, 2016.

SENTURK, S.; TEMIZEL, M. Clinical efficacy of rifamycin SV combined with oxytetracycline in the treatment of caseous lymphadenitis in sheep. Vet. Records, [S.I], v. 159, n. 7, p. 216-217, 2006.

SMITH, M.C.; SHERMAN, D. M. Goat medicine. In: __. Subcutaneous swellings. 2 th. Singapore: U.S. Library of Congress, 2009. Chapter 3. p. 63-67.

SOARES, S. C. et al. Genome sequence of Corynebacterium pseudotuberculosis biovar equi strain 258 and prediction of antigenic targets to improve biotechnological vaccine production. J. Biotechnol., Amsterdam, v.167. p. 135-141, 2013.

SUTHERLAND, S. S.; SPEIJERS, E. J.; ANDRES, B. Comparison of the exotoxins of four strains of Corynebacterium pseudotuberculosis. Res. vet. sci., London, v. 47, n.2, p. 190-194, 1989.

TELLO, A.; AUSTIN, B.; TELFER, T. C. Selective Pressure of Antibiotic Pollution on Bacteria of Importance to Public Health. Environ. health perspect., Research Triangle Park, v. 120, n. 8, p. 1100-1106, 2012.

WASHBURN, K. E. et al. Caprine abscess model of tulathromycin concentrations in interstitial fluid from tissue chambers inoculated with Corynebacterium pseudotuberculosis following subcutaneous or intrachamber administration. Antimicrob. agents chemoth., Washington, v. 57, n. 12, p. 6295-6304, 2013.

WILLIAMSON, L. H. Caseous Lymphadenitis in small ruminants. Vet. Clin. North Am. Food Anim. Prac., United States, v.17, n. 2, p.359-371, 2001.

Submetido em: $14 / 11 / 2018$

Aceito em: 29/11/2018 